\title{
ATIVIDADE ANTIOXIDANTE E ANTIMICROBIANA DE EXTRATOS DE ATEMOIA (Annona cherimola Mill. x A. squamosa L.) ${ }^{1}$
}

\author{
SUZANA VIEIRA RABÊLO², MATEUS MATIUZZI DA COSTA ${ }^{3}$, RAFAEL CUNHA LIBÓRIO ${ }^{4}$, \\ JACKSON ROBERTO GUEDES DA SILVA ALMEIDA ${ }^{5}$
}

RESUMO - O objetivo deste trabalho foi quantificar os teores de fenóis e flavonoides totais, bem como avaliar as atividades antioxidante e antimicrobiana de extratos obtidos dos talos e folhas de atemoia (A. cherimola Mill. x A. squamosa L.), que pertence à família Annonaceae. A atividade antioxidante foi avaliada pelos métodos de sequestro dos radicais 2,2-difenil-1-picrilhidrazil (DPPH) e 2,2' -azinobis-3-etilbenzotiazolina-6ácido sulfônico (ABTS), bem como pelo método da cooxidação do $\beta$-caroteno/ácido linoleico. A avaliação da atividade antimicrobiana dos extratos foi analisada contra 10 cepas de bactérias. Os resultados da atividade antioxidante dos extratos mostraram que o extrato etanólico dos talos (EEt) foi o antioxidante mais efetivo $\left(\mathrm{IC}_{50}=10,44 \pm 1,25 \mu \mathrm{g} / \mathrm{mL}\right)$ no método do sequestro do DPPH, bem como no sequestro do radical ABTS $(24,81 \pm 0,49 \%)$. O extrato hexânico das folhas apresentou o melhor percentual de atividade antioxidante no ensaio do $\beta$-caroteno/ácido linoleico $(41,12 \pm 4,35 \%)$. Os extratos etanólico dos talos e metanólico das folhas mostraram-se ativos contra cepas de Bacillus cereus, Klebsiella pneumoniae, Staphylococcus aureus resistente à meticilina (MRSA), Staphylococcus aureus e Staphylococcus epidermidis.

Termos para indexação: plantas medicinais, atemoia, atividade antibacteriana, radicais livres.

\section{ANTIOXIDANT AND ANTIMICROBIAL ACTIVITY OF EXTRACTS FROM ATEMOIA (Annona cherimola Mill. x A. squamosa L.)}

\begin{abstract}
The aim of this study was to quantify the levels of total phenols and flavonoids as well as to evaluate the antioxidant and antimicrobial activities of extracts obtained from stems and leaves of atemoia (A. cherimola Mill. x A. squamosa L.), which belongs to the Annonaceae family. The antioxidant activity was evaluated by using 2,2-diphenyl-1-picrylhydrazyl (DPPH) and 2,2'-azinobis-3-ethylbenzothiazoline-6sulfonic acid (ABTS) scavengers methods, as well as the method of co-oxidation of $\beta$-carotene/linoleic acid. The antimicrobial activity of the extracts was assessed against 10 strains of bacteria. The results showed that the antioxidant activity of the ethanolic extract from the stems (EEt) was the most effective antioxidant $\left(\mathrm{IC}_{50}\right.$ $=10.44 \pm 1.25 \mathrm{mg} / \mathrm{ml})$ by the DPPH method, as well as in the ABTS radical scavenger $(24.81 \pm 0.49 \%)$. The hexane extract of the leaves showed the best percentage of antioxidant activity by $\beta$-carotene/linoleic acid test $(41.12 \pm 4.35 \%)$. The ethanolic and metabolic extracts were active against strains of Bacillus cereus, Klebsiella pneumoniae, Methicillin-resistant Staphylococcus aureus (MRSA), Staphylococcus aureus and Staphylococcus epidermidis.
\end{abstract}

Index terms: medicinal plants, atemoia, antibacterial activity, free radicals.

\footnotetext{
${ }^{1}$ (Trabalho 119-13) - Recebido em: 14-03-2013. Aceito para publicação em: 12-11- 2013. V Congresso Internacional \& Encontro Brasileiro sobre Annonaceae: do gene à exportação (19 a 23 de Agosto de 2013)-Botucatu-SP.

${ }^{2}$ Mestranda em Recursos Naturais do Semiárido, Universidade Federal do Vale do São Francisco, 56.304-205, Petrolina-PE, Brasil. E-mail: suzana_rabelo@yahoo.com.br, Bolsista FACEPE.

${ }^{3}$ Ph.D., Universidade Federal do Vale do São Francisco, Petrolina-PE, Brasil. E-mail: mateus.costa@univasf.edu.br

${ }^{4}$ Mestrando em Recursos Naturais do Semiárido, Universidade Federal do Vale do São Francisco, Petrolina-PE, Brasil. E-mail: rafael. liborio17@gmail.com, Bolsista CAPES.

${ }^{5}$ Ph.D., Núcleo de Estudos e Pesquisas de Plantas Medicinais, Universidade Federal do Vale do São Francisco, Petrolina-PE, Brasil. E-mail: jackson.guedes@univasf.edu.br
} 


\section{INTRODUÇÃO}

A família Annonaceae compreende um grande número de gêneros e espécies, cuja maioria é nativa das regiões tropicais, com cerca de 2.500 espécies distribuídas em aproximadamente 135 gêneros (ALMEIDA et al., 2012). No Brasil, foram registrados 29 gêneros, compreendendo cerca de 260 espécies (PONTES et al., 2004).

Dados quimiotaxonômicos caracterizam esta família pela presença de alcaloides, flavonoides e terpenoides, principalmente diterpenos (SILVA et al., 2009). Recentemente, os estudos sobre fitoquímica e atividade biológica das anonáceas estão sendo intensificados devido à presença das acetogeninas, que são uma classe de compostos com ampla atividade biológica (MATSUMOTO et al., 2010), tais como citotóxica, imunossupressora, pesticida, antiparasitária e antimicrobiana (LIMA et al., 2010).

A atemoia (Annona cherimola Mill. $\mathrm{x}$ Annona squamosa L.) é um híbrido interespecífico entre a cherimólia ( $A$. cherimola Mill.) e a pinha ou fruta-do-conde (A. squamosa L.) (OLIVEIRA et al., 2010). Apesar de o cruzamento entre espécies ocorrer naturalmente, o híbrido atemoia foi resultado de um cruzamento intencional, com o objetivo de se obter um fruto de tão boa qualidade quanto a cherimólia, e que se adaptasse melhor ao clima tropical. A atemoia é de cultivo recente no Nordeste, tendo sido inserida pela primeira vez na região, nos projetos de irrigação do Vale do São Francisco, em 1997. Alguns estudos sobre fisiologia e qualidade pós-colheita foram realizados com esta planta (SCALOPPIJUNIOR; MARTINS, 2003; OLIVEIRA et al., 2010; PEREIRA; KAVATI, 2011). Já os estudos sobre fitoquímica e atividade biológica ainda são escassos no Brasil.

O presente trabalho teve como objetivo determinar os teores de fenóis e flavonoides totais, assim como avaliar as atividades antioxidante e antimicrobiana de extratos de atemoia (Annona cherimola Mill. x A. squamosa L.).

\section{MATERIAL E MÉTODOS}

Coleta do material vegetal: Folhas e caules de atemoia foram coletados em Petrolina (Coordenadas: 9'23'19" S e 40²9'3” W), Estado de Pernambuco, Brasil, no mês de maio de 2012. A identidade botânica da planta foi confirmada pelo professor José Alves de Siqueira Filho, e uma exsicata (16310) encontra-se depositada no Herbário Vale do São Francisco (HVASF) da Universidade Federal do Vale do São Francisco (UNIVASF).

Processamento do material vegetal e obtenção dos extratos-As partes coletadas da espécie foram submetidas, separadamente, à secagem em estufa com circulação de ar a $45{ }^{\circ} \mathrm{C}$, por sete dias consecutivos. Ao final, as partes foram trituradas em moinho mecânico, fornecendo $881 \mathrm{~g}$ de folhas e $371 \mathrm{~g}$ de talos. As folhas secas e pulverizadas foram maceradas com hexano (440 g do pó seco em $2 \mathrm{~L}$ de solvente) e metanol (440 g de pó seco em 1,5 L de solvente) à temperatura ambiente. Os talos foram submetidos à maceração com álcool etílico $(371 \mathrm{~g}$ de pó seco em $2 \mathrm{~L}$ de solvente). Para cada procedimento, foram realizadas 3 extrações num intervalo de 72 horas entre cada extração. As soluções extrativas obtidas foram concentradas em evaporador rotativo sob pressão reduzida, e após evaporação do solvente, obtiveram-se os extratos hexânico (EHf - 63 g) e metanólico (EMf - $169 \mathrm{~g}$ ) das folhas e o extrato etanólico dos talos (EEt $-33 \mathrm{~g})$.

Avaliação da atividade antioxidante in vitro- A atividade antioxidante usando o método do sequestro do radical livre estável 2,2-difenil1-picrilhidrazil (DPPH) foi realizada usando metodologia descrita por Falcão et al. (2006). Os resultados obtidos foram comparados com os antioxidantes comerciais ácido ascórbico, butilhidroxianisol (BHA) e butilhidroxitolueno (BHT). A capacidade para sequestrar o cátion radical 2,2'-azinobis-3-etilbenzotiazolina-6-ácido sulfônico $\left(\mathrm{ABTS}^{+}\right)$foi determinada de acordo com metodologia descrita por Chen et al. (2011). A solução de $\mathrm{ABTS}^{+}$ foi preparada pela reação de ABTS $7 \mathrm{mM}(5 \mathrm{~mL})$ e $2,45 \mathrm{mM}(88 \mu \mathrm{L})$ de persulfato de potássio, após incubação à temperatura ambiente no escuro, durante 16 h. Foi então diluída com etanol a $80 \%$ para se obter uma absorbância de $0,700 \pm 0,005$ a $734 \mathrm{~nm}$. A solução $\mathrm{ABTS}^{+}(2,7 \mathrm{~mL})$ foi cuidadosamente misturada com $0,3 \mathrm{~mL}$ das amostras do teste. A mistura de reação foi deixada em repouso a 30 ${ }^{\circ} \mathrm{C}$, durante $30 \mathrm{~min}$, e a absorbância a $734 \mathrm{~nm}$ foi medida em espectrofotômetro (Marca QUIMIS, modelo Q798U2M). Amostras de Trolox com as mesmas concentrações foram usadas como padrões. No método da cooxidação do $\beta$-caroteno frente ao ácido linoleico foi utilizada a metodologia descrita por Chen et al. (2011).

Determinação de fenóis totais- O conteúdo de compostos fenólicos totais foi medido em triplicata para cada extrato, conforme o método de Slinkard e Singleton (1977), com adaptações propostas por Almeida et al. (2011), usando o reagente de FolinCiocalteu e soluções-padrão de ácido gálico na faixa de concentração de 50-1000 mg/L. O teor de 
fenóis totais, expresso em $\mathrm{mg}$ de equivalentes de ácido gálico por grama de amostra (mg EqAG/g), foi calculado a partir da equação da reta obtida para a curva de calibração. Todas as análises foram realizadas em triplicata.

Determinação do teor de flavonoides totaisO teor de flavonoides totais foi determinado pelo método colorimétrico descrito por Dewanto et al. (2002), usando soluções-padrão de catequina na faixa de concentração de 50-1.000 mg/L. O teor de flavonoides totais, expresso em $\mathrm{mg}$ de equivalentes de catequina por grama de amostra (mg EqC/g), foi calculado a partir da equação da reta obtida para a curva de calibração. Todas as análises foram realizadas em triplicata.

Avaliação da atividade antimicrobiana- A avaliação da atividade antimicrobiana dos extratos foi realizada frente às cepas de Bacillus cereus, Enterococcus faecalis, Escherichia coli, Klebisiella pneumoniae, Salmonella choleraesuis, Serratia marcescens, Shigella flexneri, Staphylococcus aureus, Staphylococcus epidermidis [ATCC 12228] e um isolado clínico de Staphylococcus aureus resistente à meticilina (MRSA). A atividade foi determinada por meio do protocolo de microdiluição, baseando-se no documento M7-A7 do Clinical and Laboratory Standard Institute (CLSI), com modificações propostas por Oliveira-Júnior et al. (2012). Os três extratos (EEt, EHf e EMf) foram ajustados à concentração de $25.000 \mu \mathrm{g} / \mathrm{mL}$ e submetidos a diluições em série, obtendo-se as concentrações de $12.500 ; 6.250 ; 3.125 ; 1.562,5$; 781,$2 ; 390,6 ; 195,3$ e 97,6 $\mu \mathrm{g} / \mathrm{mL}$. No preparo do inóculo, colônias foram desenvolvidas em ágar Muller-Hinton (MH) e então suspensas em solução com turbidez equivalente à escala 0,5 de McFarland. Desta suspensão, $10 \mu \mathrm{L}$ foram inoculados nos poços de microplacas contendo as diluições seriadas dos extratos. As placas foram incubadas a $37^{\circ} \mathrm{C}$, por 24 h. Com auxílio de um replicador, alíquotas foram retiradas das microplacas e semeadas na superfície de placas de Petri contendo ágar $\mathrm{MH}$, sendo incubadas a $37{ }^{\circ} \mathrm{C}$, por $24 \mathrm{~h}$. A concentração bactericida mínima (CBM) foi definida como sendo a menor concentração do extrato capaz de causar a morte do inóculo bacteriano. Os testes foram realizados em triplicata.

\section{RESULTADOS E DISCUSSÃO}

Análises de atividade antioxidante, utilizando os radicais DPPH, ABTS, e ensaio usando a cooxidação do $\beta$-caroteno frente ao ácido linoleico têm sido muito utilizados para verificar a capacidade sequestradora de radicais livres de muitos produtos naturais (LI et al., 2011; ALVES et al., 2010).

$\mathrm{Na}$ Tabela 1, são apresentados os resultados das avaliações da atividade antioxidante, bem como da quantificação estimada da concentração de fenóis e flavonoides totais dos extratos obtidos das partes aéreas da atemoia.

O EEt foi o antioxidante mais efetivo no ensaio do sequestro do DPPH $\left(\mathrm{IC}_{50}=10,44 \pm 1,25\right.$ $\mu \mathrm{g} / \mathrm{mL}$ ), obtendo melhor atividade que a do padrão sintético BHT $\left(\mathrm{IC}_{50}=17,67 \pm 3,66 \mu \mathrm{g} / \mathrm{mL}\right)$. Esta alta atividade sequestradora de radicais livres para o EEt pode ser explicada pela presença de compostos fenólicos $(207,80 \pm 7,21 \mathrm{mg} \mathrm{EqAG} / \mathrm{g})$ e de flavonoides $(151,96 \pm 7,30 \mathrm{mg} \mathrm{EqC} / \mathrm{g}) \mathrm{em}$ maior concentração quando comparados aos outros extratos. Os compostos fenólicos impedem a ação de radicais livres no organismo e, uma vez que protegem moléculas como o DNA, podem vir a abortar alguns processos carcinogênicos (SILVA et al., 2010). O teor de compostos fenólicos no extrato etanólico dos talos está diretamente ligado ao resultado da atividade antioxidante pelo método do sequestro do radical DPPH, uma vez que estas substâncias podem reduzir este radical à sua forma menos reativa, a hidrazina, por meio da fixação de um hidrogênio que é removido das substâncias fenólicas (SOUSA et al., 2007).

No método do ABTS, o EEt também apresentou melhor atividade antioxidante $(24,81 \pm$ $0,49 \%$ ) quando comparado aos demais extratos. Essa atividade foi inferior ao padrão Trolox, que apresentou $52,98 \pm 0,69 \%$ de atividade sequestradora do radical, seguida em ordem decrescente de percentual de atividade antioxidante, pelo EMf e EHf, com 10,07 \pm 0,72 e $-7,15 \pm 11,08 \%$, respectivamente. Acredita-se que este valor negativo de porcentagem de atividade antioxidante (\%AA) esteja relacionado às substâncias presentes no extrato, que ao invés de atuarem como bons doadores de elétrons ou hidrogênio, reduzindo consequentemente o radical ABTS, promoveram efeito contrário, agindo então como agente próoxidante. Estudos estão sendo desenvolvidos para o isolamento dos constituintes químicos dos extratos.

De acordo com Kuskoski et al. (2005), as metodologias utilizando o sequestro dos radicais DPPH e ABTS medem a atividade de compostos de natureza hidrofílica. A metodologia utilizando a cooxidação do $\beta$-caroteno, por sua vez, mede a atividade de compostos de natureza lipofílica. Nesta metodologia, é medida a capacidade que os extratos têm de inibir a oxidação do $\beta$-caroteno, frente ao ácido linoleico. Nesta análise, o EHf obteve o melhor resultado para a atividade antioxidante, 
com percentual de 41,12 $\pm 4,35 \%$. O EMf obteve $20,46 \pm 5,50 \%$ e o EEt $16,21 \pm 1,97 \%$ de atividade antioxidante. As atividades antioxidantes observadas estão diretamente ligadas aos teores de fenóis e de flavonoides totais nos extratos. Os antioxidantes comerciais BHA e BHT foram mais efetivos neste modelo, apresentando percentuais de atividade antioxidante de 83,11 $\pm 1,94$ e 85,92 $\pm 5,90$, respectivamente.

Das dez cepas bacterianas que foram submetidas ao teste de sensibilidade aos extratos de atemoia, as cepas de Enterococcus faecalis, Escherichia coli, Salmonella choleraesuis, Serratia marcescens e Shigella flexneri mostraram-se resistentes aos três extratos testados, sendo a primeira um microrganismo Gram-positivo, e as demais, Gram-negativas. As cepas de Staphylococcus aureus, Staphylococcus epidermidis, Bacillus cereus, Staphylococcus aureus resistente à meticilina (MRSA) e Klebisiella pneumoniae (esta última, uma Gram-negativa) foram sensíveis à ação dos extratos etanólico e metanólico, gerando valores de CBM variando entre 781,2 e $6.250 \mu \mathrm{g} / \mathrm{mL}$ e de 3.125 a $12.500 \mu \mathrm{g} / \mathrm{mL}$, respectivamente. Todas as cepas mostraram-se resistentes ao extrato hexânico. Na Figura 1, são apresentados os resultados obtidos. Destacamos a ação do extrato etanólico sobre a cepa de Staphylococcus aureus resistente à meticilina (MRSA). Além de representar um dos principais patógenos associados a infecções hospitalares, o $S$. aureus é também um dos principais agentes isolados de pacientes com infecções de pele, e essas cepas foram incluídas em nosso estudo porque são resistentes a todos os antimicrobianos betalactâmicos (GELATTI et al., 2009). Em nosso estudo, a cepa mostrou-se sensível à ação do extrato etanólico, o que nos motiva a dar continuidade ao estudo deste extrato em relação à atividade antibacteriana. Em estudo de atividade antimicrobiana, utilizando-se de folhas de Anonna squamosa, Chandrashekar e Kulkarni (2011) observaram atividade do extrato sobre cepas de Pseudomonas aeruginosa, Bacillus subtilis, S. aureus e Salmonella typhi, sem observar atividade sobre fungos do gênero Aspergillus. Aher et al. (2012) avaliaram o potencial antimicrobiano de extratos das sementes de $A$. squamosa, constatando que a fração metanólica apresentou maior atividade antimicrobiana contra cepas de B. subitilis, S. aureus, K. pneumoniae, E. coli e P. aeruginosa.

Notadamente, microrganismos Gramnegativos mostram-se mais resistentes à ação de antimicrobianos, uma vez que sua parede celular se encontra protegida por uma camada de lipopolissacarídeos (GOULD, 2009). Das dez cepas testadas, cinco (50\%) são classificadas como microrganismos Gram-positivos, e outras cinco, como Gram-negativos. Observou-se que das cinco cepas suscetíveis a pelo menos uma fração do extrato, quatro pertencem ao grupo das Gram-positivas, e $K$. pneumoniae foi a única cepa Gram-negativa sensível.

Dos três extratos avaliados no estudo, apenas os extratos etanólico e metanólico produziram algum efeito antimicrobiano. Acredita-se que muito do efeito antimicrobiano dos extratos vegetais se deve, principalmente, à presença de flavonoides em sua composição (AHMAD; BEG 2001). Durante a obtenção dos extratos, baseando-se na polaridade de seus constituintes, o extrato hexânico conservou-se pobre em flavonoides e rico em terpenoides. Devido a esse fato, provavelmente, observa-se fraca ou nenhuma ação antimicrobiana do extrato hexânico das folhas.

Devido à maior suscetibilidade de microrganismos Gram-positivos, acredita-se que o mecanismo da ação antimicrobiana do extrato, provavelmente, decorra da interação do mesmo com o peptidoglicano presente na parede celular bacteriana, e que caracteriza uma barreira mais frágil do que a parede celular das bactérias Gram-negativas. No entanto, estudos posteriores, visando à elucidação desse mecanismo, devem ser conduzidos. 
TABELA 1 - Fenóis totais, flavonoides totais e atividade antioxidante in vitro dos extratos de atemoia.

\begin{tabular}{cccccc}
\hline \multirow{2}{*}{ Amostra } & $\begin{array}{c}\text { Fenóis totais } \\
(\mathbf{m g E q A G} / \mathbf{g})\end{array}$ & $\begin{array}{c}\text { Flavonoides totais } \\
(\mathbf{m g E q C} / \mathbf{g})\end{array}$ & $\left.\begin{array}{c}\mathbf{D P P H} \\
(\mathbf{I C}\end{array} \mathbf{5 0}, \boldsymbol{\mu g} / \mathbf{m l}\right)$ & $\begin{array}{c}\text { ABTS } \\
\mathbf{( \% A A )}\end{array}$ & $\begin{array}{c}\boldsymbol{\beta} \text {-caroteno } \\
\mathbf{( \% A A )}\end{array}$ \\
\hline EEt & $207,80 \pm 7,21$ & $151,96 \pm 7,30$ & $10,44 \pm 1,25$ & $24,81 \pm 0,49$ & $16,21 \pm 1,97$ \\
EHf & $74,47 \pm 7,50$ & $14,90 \pm 4,00$ & $186,00 \pm 3,06$ & $-7,15 \pm 11,08$ & $41,12 \pm 4,35$ \\
EMf & $75,80 \pm 2,64$ & $46,86 \pm 2,90$ & $29,87 \pm 5,12$ & $10,07 \pm 0,72$ & $20,46 \pm 5,50$ \\
Ácido ascórbico & --- & --- & $2,57 \pm 0,09$ & --- & $7,63 \pm 1,48$ \\
BHA & --- & --- & $4,13 \pm 0,31$ & --- & $83,11 \pm 1,94$ \\
BHT & --- & --- & $17,67 \pm 3,66$ & --- & $85,92 \pm 5,90$ \\
Trolox & --- & --- & --- & $52,98 \pm 0,69$ & -- \\
\hline
\end{tabular}

Os valores de $\mathrm{IC}_{50}$ foram obtidos por interpolação a partir da análise de regressão linear, com $95 \%$ de nível de confiança. $\mathrm{IC}_{50}$ é definido como a concentração suficiente para se obter $50 \%$ do efeito máximo de uma estimativa de $100 \%$. Os valores são dados como média \pm DP $(n=3)$. EEt: extrato etanólico dos talos; EHf: extrato hexânico das folhas; EMf: extrato metanólico das folhas; BHA: butilhidroxianisol; BHT: butilhidroxitolueno; mg EqAG: miligramas de equivalente de ácido gálico; mg EqC: miligramas de equivalente de catequina; DPPH: 2,2-difenil-1-picrilhidrazil; ABTS: 2,2'-azinobis-3-etilbenzotiazolina-6-ácido sulfônico; AA: atividade antioxidante.

\section{Concentração bactericida mínima dos extratos de atemoia $(\mu \mathrm{g} / \mathrm{mL})$.}

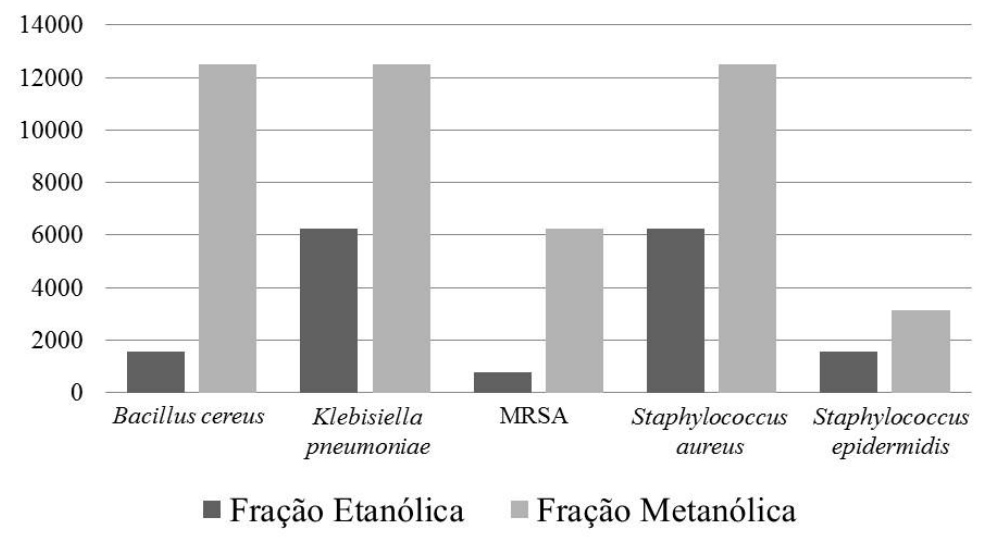

FIGURA 1 - Atividade antimicrobiana dos extratos etanólico e metanólico das folhas de atemoia.

\section{CONCLUSÕES}

Os resultados apresentados neste estudo mostram que a atemoia possui atividades antioxidante e antimicrobiana. As atividades apresentadas podem estar relacionadas à presença de substâncias fenólicas nos extratos, principalmente os flavonoides. Estudos estão sendo realizados para o isolamento dos constituintes químicos desta espécie, para que os mesmos possam ser testados em modelos experimentais, e, assim, determinarmos os compostos responsáveis pelas atividades biológicas dos extratos.

\section{AGRADECIMENTOS}

Os autores agradecem ao CNPq, pelo apoio financeiro para a realização da pesquisa, bem como à FACEPE e à CAPES, pelas bolsas de mestrado concedidas. Agradecemos também ao CRAD/ UNIVASF, pela identificação botânica da planta. 


\section{REFERÊNCIAS}

AHER, P. S.; SHINDE, Y. S.; CHAVAN, P. P. In vitro evaluation of antibacterial potential of Annona squamosa L. against pathogenic bacteria. International Journal of Pharmaceutical Sciences and Research, Chandigarh, v. 3, n. 5, p. 1.457-1.460, 2012.

AHMAD, I.; BEG, A. Z. Antimicrobial and phytochemical studies on 45 Indian medicinal plants against multi-drug resistant human pathogens. Journal of Ethnopharmacology, Amsterdam, v. 74, p. 113-123, 2001.

ALMEIDA, J. R. G. S.; ARAÚJO, E. C. C.; RIBEIRO, L. A. A.; LIMA, J. T.; NUNES, X. P.; LÚCIO, A. S. S. C.; AGRA, M. F.; BARBOSA-FILHO, J. M. Antinociceptive activity of ethanol extract from Duguetia chrysocarpa Maas (Annonaceae). The Scientific World Journal, Cairo, v. 2012, p. 1-6, 2012.

ALMEIDA, J. R. G. S.; OLIVEIRA, M. R.; GUIMARÃES, A. L.; OLIVEIRA, A. P.; RIBEIRO, L. A. A.; LÚCIO, A. S. S. C.; QUINTANS-JÚNIOR, L. J. Phenolic quantification and antioxidant activity of Anaxagorea dolichocarpa and Duguetia chrysocarpa (Annonaceae). International Journal of Pharma and Bio Science, Andhra Pradesh, v. 2, n. 4, p. 367-374, 2011

ALVES, C. Q.; DAVID, J. M.; DAVID, J. P.; BAHIA, M. V.; AGUIAR, R. M. Métodos para determinação de atividade antioxidante in vitro em substratos orgânicos. Química Nova, São Paulo, v. 33, n. 10, p. 2.202-2.210, 2010.

CHANDRASHEKAR, C.; KULKARNI, V. R. Isolation, characterization and antimicrobial activity of Annona squamosa leaf. Journal of Pharmacy Research, Melbourne, v. 4, n. 6, p. 1.831-1.832, 2011.

CHEN, Y.; HUANG, B.; HE, J.; HAN, L.; ZHAN, Y.; WANG, Y. In vitro and in vivo antioxidant effects of the ethanolic extract of Swertia chirayita. Journal of Ethnopharmacology, Amsterdam, v. 136, n. 2, p. 309-315, 2011.

DEWANTO, V.; WU, X.; ADOM, K.; LIU, R. H. J. Processed sweet corn has higher antioxidant activity. Journal of Agricultural and Food Chemistry, Washington, v. 50, n. 10, p. 3.010-3.014, 2002.
FALCÃO, D. Q.; COSTA, E. R.; ALVIANO, D. S.; ALVIANO, C. S.; KUSTER R. M.; MENEZES, F. S. Atividade antioxidante e antimicrobiana de Calceolaria chelidonioides Humb. Revista Brasileira de Farmacognosia, Curitiba, v. 16, n. 1, p. 73-76, 2006.

GELATTI, L. C.; BONAMIGO, R. R.; BECKER, A. P.; D'AZEVEDO, P. A. Staphylococcus aureus resistentes à meticilina: disseminação emergente na comunidade. Anais Brasileiros de Dermatologia, Rio de Janeiro, v. 84, n. 5, 501-506, 2009.

GOULD, D. Effective strategies for prevention and control of Gram-negative infections. Nursing Standard, Londres, v. 23, n. 48, p. 42-46, 2009.

KUSKOSKI, E. M.; ASUERO, A. G.; TRONCOSO, A. M.; MANCINI FILHO, J.; FETT, R. Aplicatíon de diversos métodos químicos para determinar actividad antioxidante en pulpa de frutos. Ciência e Tecnologia de Alimentos, Campinas, v. 25, n. 4 , p. 726-732, 2005 .

LI, P.; HUO, L.; SU, W.; LU, R.; DENG, C.; LIU, L.; DENG, Y.; GUO, N.; LU, C.; HE, C. Free radical-scavenging capacity, antioxidant activity and phenolic content of Pouzolzia zeylanica. Journal of the Serbian Chemical Society, Belgrado, v. 76, n. 5, p. 709-717, 2011.

LIMA, L. A. R. S.; PIMENTA, L. P. S.; BOAVENTURA, M. A. D. Acetogenins from Annona cornifolia and their antioxidant capacity. Food Chemistry, Reading, v. 122, n. 4, p. 1.1291.138, 2010.

MATSUMOTO, R. S.; RIBEIRO, J. P. N.; TAKAO, L. K.; LIMA, M. I. S. Allelopathic potential of leaf extract of Annona glabra L. (Annonaceae). Acta Botanica Brasilica, Feira de Santana, v. 24, n. 3, p. 631-635, 2010.

OLIVEIRA, M. C.; FERREIRA, G.; GUIMARÃES, V. F.; DIAS, G. B. Germinação de sementes de atemoia (Annona cherimola Mill. x A. squamosa L.) CV 'GEFNER' submetidas a tratamentos com ácido giberélico $\left(\mathrm{GA}_{3}\right)$ e ethephon. Revista Brasileira de Fruticultura, Jaboticabal, v. 32, n. 2, p. 544-554, 2010. 
OLIVEIRA-JÚNIOR, R. G.; ARAÚJO, C. S.; SANTANA, C. R. R.; SOUZA, G. R.; LIMASARAIVA, S. R. G.; GUIMARÃES, A. L.; OLIVEIRA, A. P.; SIQUEIRA-FILHO, J. A.; PACHECO, A. G. M.; ALMEIDA, J. R. G. S. Phytochemical screening, antioxidant and antibacterial activity of extracts from the flowers of Neoglaziovia variegata (Bromeliaceae). Journal of Chemical and Pharmaceutical Research, Rajasthan, v. 4, n. 10, p. 4.489-4.494, 2012.

PEREIRA, F. M.; KAVATI, R. Contribuição da pesquisa científica brasileira no desenvolvimento de algumas frutíferas de clima subtropical. Revista Brasileira de Fruticultura, Jaboticabal, p. E. 092108, 2011. Volume especial.

PONTES, A. F.; BARBOSA, M. R. V.; MAAS, P. J. M. Flora Paraibana: Annonaceae Juss. Acta Botanica Brasilica, Feira de Santana, v. 18, n. 2, p. 281-293, 2004.

SCALOPPI-JÚNIOR, E. J.; MARTINS, A. B. G. Clonagem de quatro espécies de Annonaceae potenciais como porta-enxertos. Revista Brasileira de Fruticultura, Jaboticabal, v. 25, n. 2, p. 286-289, 2003.
SILVA, M. L. C.; COSTA, R. S.; SANTANA, A. S.; KOBLITZ, M. G. B. Compostos fenólicos, carotenoides e atividade antioxidante em produtos vegetais. Semina: Ciências Agrárias, Londrina, v. 31, n. 3, p. 669-682, 2010.

SILVA, M. S.; TAVARES, J. F.; QUEIROGA, K. F.; AGRA, M. F.; BARBOSA-FILHO, J. M.; ALMEIDA, J. R. G. S.; SILVA, S. A. S. Alkaloids and other constituents from Xylopia langsdorffiana (Annonaceae). Química Nova, São Paulo, v. 32, n. 6, p. 1.566-1.570, 2009.

SLINKARD, K.; SINGLETON, V. L. Total phenol analyses automation and comparison with manual methods. American Journal of Enology and Viticulture, Washington, v. 28, p. 49-55, 1977.

SOUSA, C. M. M.; SILVA, H. R. S.; VIEIRAJÚNIOR, G. M.; AYRES, M. C. C.; COSTA, C. L. S.; ARAÚJO, D. S.; CAVALCANTE, L. C. D.; BARROS, E. D. S.; ARAÚJO, P. B. M.; BRANDÃO, M. S.; CHAVES, M. H. Fenóis totais e atividade antioxidante de cinco plantas medicinais. Química Nova, São Paulo, v. 30, n. 2, p. 351-355, 2007. 